\title{
Las publicaciones científicas médicas impresas y su evolución hacia la era digital
}

\author{
Tunia Gil Hernández \\ Cardiocentro Ernesto Che Guevara - Cuba \\ Vivian Martínez Ruiz \\ Guillermo García Ferrer \\ Odalys Quesada Ravelo
}

Universidad de Ciencias Médicas de Villa Clara - UCMVC, Cuba

\section{ANÁLISIS}

\begin{abstract}
Resumen
En este artículo se analiza la evolución histórica de las publicaciones médicas cubanas a través del tiempo, desde su aparición en formato impreso hasta la era digital. Se hace referencia a las primeras formas de comunicación científica en el mundo, la aparición de la imprenta en América y a los acontecimientos históricos y sociales que favorecieron el nacimiento y desarrollo de las publicaciones impresas en la isla de Cuba, así como su desarrollo en la era digital.
\end{abstract}

Palabras clave

Publicaciones científicas médicas ; Publicaciones impresas ; Publicaciones electrónicas ; Cuba

\section{Medical scientific publications printed and its evolution into the digital age}

\section{Abstract}

This article analyzes the historical evolution of the Cuban medical publications over time, from its appearance in print to the digital age. Reference is made to the first forms of scientific communication in the world, the advent of printing in America and the historical and social events that favored the birth and development of printed publications on the island of Cuba, as well as its development in the digital age.

Keywords

Medical scientific publications ; Printed publications ; Electronic publications ; Cuba

\section{Introducción}

Los conocimientos, científicos o de otra clase, no pudieron transmitirse eficazmente hasta que se dispuso de mecanismos apropiados de comunicación. Los hombres prehistóricos podían comunicarse en forma oral, pero sin documentos escritos a los que acudir, los conocimientos se perdían tan rápidamente como se adquirían ${ }^{1}$.

Entre los primeros intentos de comunicación se encuentran pinturas rupestres y las inscripciones grabadas en las rocas, que permitieron que los "mensajes" primitivos sobrevivieran los embates del tiempo, pero hacía falta un medio 
de comunicación que pesara poco y fuera portátil. Los primeros medios que tuvieron éxito fueron el papiro el pergamino, pero en el año 105, de nuestra era, los chinos inventaron el papel, el medio moderno de comunicación. Al no existir una manera eficaz de reproducir las comunicaciones, los conocimientos no podían difundirse ampliamente. La aparición de la imprenta fue mayor invento de la historia intelectual de la humanidad y aunque su tipo móvil apareció en china; en el occidente se le atribuye su aparición al alemán Gutenberg ${ }^{1}$.

En América, el primer país que contó con imprenta fue México (1539), unos 180 años después es que llega a Cuba hacia 1720 y casi ciento cuarenta después a Perú, cuando ya había sido establecida en Guatemala, Paraguay y Brasil.

La Habana fue la séptima ciudad de la América española que tuvo imprenta. La historia de la imprenta en Cuba no comienza, sin embargo, hasta 1723, fecha del primer impreso conocido: Tarjfa General de Precios de Medicina ${ }^{2}$.

El nacimiento y desarrollo de las publicaciones impresas en la isla de Cuba estuvo condicionado por diversos acontecimientos históricos y sociales. Uno de ellos fue la fundación, en 1728, de la Real y Pontificia Universidad de San Jerónimo, hecho que "originó un movimiento cultural que impulsó notablemente la profusión de publicaciones impresas en forma de libros y folletos, lo que convirtió a la imprenta en una necesidad y en un lucrativo negocio"3.

Los inicios de los estudios de medicina en Cuba y la evolución constante del pensamiento filosófico, fueron los factores que influyeron en el nacimiento de las primeras publicaciones científicas en Cuba; a partir de la fundación del Seminario de San Carlos (1773) y el desarrollo paulatino de la prensa cubana durante el Siglo XIX, fundamentalmente en la década del treinta, así como también la necesidad de encontrar los medios adecuados para comunicar y difundir masivamente los nuevos conocimientos de las ciencias, con particularidad las médicas, que ya habían alcanzado un progreso notorio dentro y fuera de la nación cubana ${ }^{4}$.

El primer libro científico en Cuba fue escrito por el sevillano Lázaro de Flores Navarro, el más notable de los médicos que ejercieron en la Mayor de las Antillas durante todo el siglo XVII ${ }^{5}$ y el primer impreso cubano conservado es una Tarjfa General de Precios de Medicina que relacionaba en orden alfabético los hombres de los medicamentos con los respectivos precios puestos en vigor durante el año $1723^{2,6}$.

Los adelantos tecnológicos alcanzados paulatinamente en este período permitieron procesos de impresión con mayor calidad y estas ventajas favorecieron, para bien de las publicaciones, el incremento de la expresión escrita del pensamiento de destacadas figuras en todas las esferas del conocimiento y de las ciencias.

Nicolás J. Gutiérrez, el cirujano hábil e innovador, introductor del estetóscopo en Cuba y fundador de la Real Academia de Ciencias Médicas, Físicas y Naturales de La Habana, fue, además, el precursor de la prensa médica nacional, al crear en 1840 el Repertorio Médico Habanero, título de la primera revista cubana especializada en medicina, creada en 1840 y que se une al Boletín Científico en 1ro. de noviembre de $1843^{7}$.

\section{El criterio}

En 1852, nació El Criterio, una publicación autodenominada periódico de medicina, farmacia y ciencias auxiliares, que tenía carácter crítico y su principal objetivo era la defensa de las ideas homeopáticas. Dejó de publicarse en el mismo año de su surgimiento y reapareció en mayo de 1871, su segunda época duró apenas cuatro meses, ya que su producción cesó definitivamente en el mes de agosto siguiente ${ }^{8}$.

\section{Gaceta Médica de La Habana}

El 1ro. de enero de 1854, salió el primer número de esta revista mensual Gaceta Médica de La Habana creada por su director, el doctor Ramón Zambrana, para divulgar en artículos los resultados de estudios sobre medicina, cirugía, farmacia y otras ciencias auxiliares. Esta publicación tuvo gran acogida por parte de la comunidad científica ${ }^{9}$. De la

Gaceta Médica de La Habana salieron sólo diez números, que formaron un volumen con 168 páginas. Su publicación se suspendió en octubre de 1854. 


\section{Revista Médica de La Habana}

Esta revista, que nació a los dos meses de desaparecida la Gaceta Médica de La Habana, fue de frecuencia mensual, y también se dedicó a la divulgación de trabajos sobre medicina, cirugía, farmacia y otras ciencias auxiliares. Logró mantenerse durante dos años y medio, período más prolongado que las demás.

La publicación de este título cesó al cabo de los 30 meses de su inicio, pues para sus redactores fue imposible seguir llevando la carga que implicaba sufragar sus costos ${ }^{7}$.

\section{La Bandera de la Homeopatía en La Habana}

Esta publicación circuló durante casi tres años, concebida para divulgar la doctrina de Hahnemann ${ }^{10}$. Cuando se inició en enero de 1856, tenía una periodicidad semanal. A partir de la primera entrega del tercer volumen comenzó a publicarse quincenalmente. Su fundador y director, el Intendente de Provincia Manuel Zapatero, fue apegado las ciencias homeopáticas, lo cual lo inspiró a crear un órgano en el que todos sus partidarios podían consignar el fruto de sus observaciones.

\section{Repertorio Económico de Medicina, Cirugía y Ciencias Naturales}

Fue creada por Rafael Agustín, quien fuera desde muy joven un activo colaborador de la prensa médica Catedrático de Terapéutica en la Universidad, y bachiller en medicina. Su primer número salió a la arena periodística el 1ro. de junio de 1856, con el objetivo de consignar en sus páginas los hechos y noticias de mayor relevancia en relación con los logros de la práctica del arte de curar ${ }^{11}$.

Circuló con frecuencia irregular y produjo dos volúmenes; el primero de ellos se extendió de junio a diciembre de 1856 con 216 páginas, mientras que el segundo abarcó de enero a mayo del año siguiente y sólo alcanzó 152 páginas. Su suspensión definitiva se produjo el 15 de mayo de $1857^{11}$.

\section{El Restaurador}

Surgió el día 1ro. de octubre de 1856 en Santiago de Cuba. Su objetivo fue brindar información vinculada con la cirugía, la farmacia y las ciencias naturales. Su fundador, director y redactor fue el Licenciado José Garófalo, un ilustre galeno español radicado en esa ciudad oriental. Fue la primera publicación de ciencias médicas producida fuera de La Habana.

Esta revista apenas dejó huellas de su existencia; se suspendió a los tres meses de su primera salida, cuando se produjo la muerte de Garófalo en Madrid, lugar hacia donde éste se había trasladado para tratar de mejorar su deteriorado estado de salud ${ }^{12}$ Revista Médica de la Isla de Cuba

Con esta publicación mensual dedicada a la medicina, la cirugía y las ciencias auxiliares, que tuvo igualmente una breve duración, reaparecieron los nombres de Julio Jacinto Le Riverend en calidad de director y de Ramón Zambrana como redactor. Su primer y único volumen lo formaron 322 páginas.

En el Siglo XIX apareció otro título cuyo propósito esencial era ofrecer información acerca de los progresos científicos, y los médicos en particular, ocurridos tanto dentro, como fuera de la isla, tal es el caso de El Eco de París $(1858)^{4}$.

En 1868 durante el movimiento insurreccional, hubo una merma editorial pero a pesar de ello surgieron importantes revistas científicas como Crónica Médico Quirúrgica de La Habana (1875-1944) una de las de más extensa vida editoriales las que se observa una mayor calidad en la manera de tratar los temas y en el trazado de los objetivos editoriales, aspectos que permitieron la supervivencia de algunas hasta el Siglo XX.

La década del ochenta indica una recuperación en la producción intelectual y también en las publicaciones científicas, favorecida por diversas razones como la obtención en Cuba del doctorado en diferentes carreras universitarias, el notable desarrollo de la cirugía y la medicina, y la fundación de importantes instituciones como la 
Sociedad Económica Amigos del País, en las que se dedicaban algunos espacios a difundir también los progresos de la medicina de entonces a nivel internacional. No debe dejar de mencionarse la revista de Medicina y Cirugía de la Habana (1896-1951).

El 10 de septiembre salió el primer número de esta revista médica, según la doctora López Serrano, una de las tres más sobresalientes del Siglo XIX*, y circuló durante 56 años hasta junio de 1951. Se imprimió en La Universal, Ruiz y Hermano, San Ignacio No. 15, en La Habana ${ }^{4}$.

En Cuba, la Academia de Ciencias es la institución que ha asumido diferentes tareas y responsabilidades con la nación y en calidad de representante de la comunidad científica. Una de sus principales líneas de trabajo se refiere a la promoción de las ciencias, en tal sentido esto se ve materializado con el renacimiento de su revista en este año 2011: Anales de la Academia de Ciencias ${ }^{7}$. Por otra parte, en el Ministerio de Salud Pública (MINSAP) existe una Vicedirección de ciencia y técnica que lleva el control de las investigaciones que se hacen en el país, y publica los resultados de ese control en diferentes revistas cubanas que se encuentran en la Biblioteca Virtual de la Salud, cuya casa editora es la Editorial de Ciencias Médicas (ECIMED), entidad que divulga los resultados de investigaciones científicas, revisiones y otros temas realizados en el país por nuestros profesionales ${ }^{13}$.

Actualmente la Editorial Ciencias Médicas de La Habana, promueve más de 64 revistas de diversas especialidades, estas se encuentran en la Biblioteca Virtual de la Salud ${ }^{14}$ del sitio Infomed, la red cubana de salud en Cuba. Esta red propició la divulgación en formato electrónico, de la literatura científica desde el año 1992, fecha en que comenzó un largo período de crisis económica en nuestro país que conllevó a una disminución del uso del papel en estas labores, debido a su alto costo.

Según consta en el Registro Nacional de Publicaciones Seriadas Cubanas ${ }^{15}$, actualmente existen 119 revistas de Medicina y Salud pública, de ellas 3 se editan solo en papel, 22 en papel y en formato electrónico; y 72 son electrónicas.

\section{Conclusiones}

La aparición de la imprenta en Cuba significó una revolución tecnológica cuyo objetivo fue divulgar el conocimiento científico y literario de la época. Ella ha tenido gran influencia en la humanidad de manera general, por las posibilidades que abrió para el fomento y mejora de los procesos de las comunicaciones escritas y su trascendencia en el tiempo. Por otra parte, con la aparición de la era electrónica muchas de las revistas médicas y de salud pública han dejado de de publicarse producto al alto costo de recursos como el papel. No obstante las publicaciones electrónicas en nuestros días, retoman elementos propios de las publicaciones impresas como son la presentación, estructura y organización de la información, a las cuales los lectores se habían habituado durante los siglos precedentes, pues son el principal medio de comunicación de los adelantos científicos en nuestro país y son la mejor vía de comunicación en la actualidad debido a la inmediatez con que los lectores reciben la información.

Actualmente ECIMED es la principal promotora de la literatura médica en formato impreso y digital de Cuba, aunque prevalece este último en el caso de las revistas médicas. 


\section{Referencias bibliográficas}

1. Durán Rodríguez M. (2008). Ciudades virtuales latinas [Internet]; [citado 13 Feb 2013]. Disponible en: http://www.rrppnet.com.ar/historiadelaimprenta.htm

2. Perelló Cabrera JL. (1989). Manual de edición y reproducción de documentos informativos. La Habana: Ministerio de Educación Superior: 48.

3. Valdés Pérez MG (2007). Publicaciones periódicas científicas. Génesis y contemporaneidad. Revista Universidad de La Habana. 54.

4. López Sánchez J. (1997). Biografías y médicos cirujanos. En: Cuba. Medicina y civilización. Siglos xvii y xviii. La Habana: Científico-Técnica. p. 252-5.

5. Vilar JB (1996). Los orígenes de la prensa cubana. Un intento de aproximación y análisis (1764-1833). Revista Complutense de Historia de América [Internet]. [citado 24 Oct 2012];22. Disponible en:

http://revistas.ucm.es/index.php/RCHA/article/viewFile/RCHA9696110337A/29068

6. Pastrana JS (2011). Dimensión y alcance actual de la Academia de Ciencias de Cuba. Anales de la Academia de Ciencias de Cuba, 1(1), 1.

7. López Espinosa J (1999). Las primeras revistas médicas cubanas de la segunda mitad del siglo XIX. Rev Cubana Salud Pública [Internet], 25(2), p. 178-90..

8. Sánchez Roig M (1939). Bibliografía de la prensa médica cubana de 1840 a 1885. La Habana: La Propagandista. p.19.

9. de Cañete JS (1998). Cuatro personajes históricos de la Medicina. Seminario Médico [Internet]. Disponible en: Dialnet-CuatroPersonajesHistoriaDeLaMedicina-12223195.pdf

10. Cowley RA (1856). Al público. Rep Econ Med Cir Cien Nat, 1(1), 1-3.

11. Le Roy Cassá J (1917). La historia y la prensa médica de Cuba. Rev Med Cir Hab, 22 (23), 617-38.

12. ECIMED [sitio web en Internet]. La Habana: Infomed; (1999-2010 [actualizado jueves, 29 Abr 2010; citado 29 Abr 2010]. Disponible en: http://www.sld.cu/sitios/ecimed/

13. BVS [sitio web en Internet]. La Habana: Infomed; (C) 1999-2012 http://bvscuba.sld.cu/revistas-medicas-cubanas/

14. Registro Nacional de Publicaciones Seriadas Cubanas [sitio web en Internet]. La Habana: http://www.seriadas.cult.cu/index.php?codigo=res_citma 


\section{Datos del autor}

Tunia Gil Hernández

Cardiocentro Ernesto Che Guevara.

tuniagh@infomed.sld.cu

Vivian Martínez Ruiz

Universidad de Ciencias Médicas de Villa Clara

vivianmr@ucm.vcl.sld.cu

Guillermo García Ferrer

Universidad de Ciencias Médicas de Villa Clara

guillermogf@ucm.vcl.sld.cu

Odalys Quesada Ravelo

Universidad de Ciencias Médicas de Villa Clara

odalysqr@ucm.vcl.sld.cu

Recibido-Received : 2013-02-15

Aceptado-Accepted : :2013-03-30

(c) EY New articles in this journal are licensed under a Creative Commons Attribution 3.0 United States License.

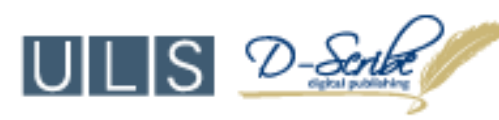

This journal is published by the University Library System of the University of Pittsburgh as part of its D-Scribe Digital Publishing Program and is cosponsored by the University of Pittsburgh Press. 